\title{
Final Machining of Large-Scale Engine Block with Modularized Fixture and Virtual Manufacturing Technologies
}

\author{
Hong Liu, ${ }^{1}$ Fan Peng, ${ }^{2}$ and Yi Liu ${ }^{2}$ \\ ${ }^{1}$ North Minzu University, Yinchuan, Ningxia 750021, China \\ ${ }^{2}$ KOCEL Machinery Limited, Yinchuan, Ningxia 750021, China \\ Correspondence should be addressed to Hong Liu; hlongiu@163.com
}

Received 17 April 2017; Revised 14 August 2017; Accepted 20 September 2017; Published 3 December 2017

Academic Editor: Jong M. Park

Copyright (c) 2017 Hong Liu et al. This is an open access article distributed under the Creative Commons Attribution License, which permits unrestricted use, distribution, and reproduction in any medium, provided the original work is properly cited.

\begin{abstract}
This paper addresses the issue of unstable machining quality of large-scale high-precision internal combustion engine block; the key machining technologies of complex thin-wall internal combustion engine block are studied. This dissertation takes the $\mathrm{L}$ type engine block that is used as research object; the modular and fast changing fixtures have been designed for machining engine blocks; due to the fact that this kind of engine blocks has different number of cylinders, we establish a model of precision machining scheme based on virtual manufacturing technology and manufacturing method; on this basis, the scheme is applied to the actual production process to verify the feasibility of the program. The research shows that the precision machining scheme established based on virtual manufacturing technology can effectively solve the key machining technology of the engine block, and one purpose of using this method is to improve machining precision and efficiency of the assembly production. This study intends to propose final machining technology project of high-precision products, and this will formulate and gradually perfect a machining process framework for large engine block, which has engineering exploration value to promote machining technology.
\end{abstract}

\section{Introduction}

Virtual manufacturing (VM) technology is one of the most important parts in the manufacturing system. Various conditions and resources affect the total efficiency and precision of the manufacturing system. The same is true of the internal combustion engine manufacturing systems.

The engine block is the largest and most intricate single component used in an internal combustion engine [1]; the traditional machining methods need to make several times on actual machining attempts that comprises a large portion among the total time in a manufacturing process; the optimization of these processes by means of VM can contribute greatly to the total efficiency and precision of a mechanical system [2]. By comparing the development trend with the current situation of large equipment machining technology, it can be concluded that it has become the inevitable requirement of the times expanding. So we should upgrade the machining technical content of large-scale engine block as soon as possible [3].
Recently, with the increasingly fierce market competition, improving the machining technology of large-scale engine block has become the urgent task for the further development.

Most of the papers were to expand the study of machining program of large engine block from the point of $\mathrm{VM}$ technology $[4,5]$. Jeffrey applied the VM technology in the manufacturing process of the internal combustion engine block, the production process and the production system model were established, and the virtual model of the internal combustion engine block was analyzed; his research realized the connection between the VM environment and the real manufacturing environment [6]. In the aspect of simulation technology, the machining process was optimized through simulation and the simulation parameters based on computer graphics display system and control technology, and it can guide the actual machining process and improve the processing efficiency $[7,8]$. In respect of the total working hours of internal combustion engine products, machining hours are still occupying a large share. The application of VM 


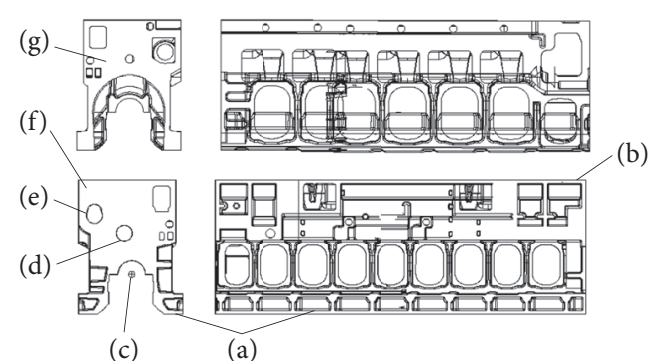

FIGURE 1: Structure of L type internal combustion engine block. (a) The bottom surface; (b) cylinder hole surface; (c) crankshaft; (d) idler wheel hole; (e) camshaft hole; (f) flywheel surface; (g) pump cover surface.

technology can effectively improve the machining efficiency but also optimize the machining process, the tool path, cutting parameters, cutting allowance, process structure, and the interference between the fixture and the workpiece [9]. Gershenson et al. put forward the modularization design method from the three aspects of the independence of the components, the independence of the process, and the similarity of the process $[10,11]$. However, fewer published literatures are available for final machining of large engine block using VM technology from the view of improving efficiency and accuracy point; this shows that the combination of VM technology and modular and fast changing ideas of the series high efficiency machining technology needs to be further studied, and this is the significance of this research work.

Motivated by the above works, the main objective of this paper is to improve the total efficiency and precision of the engine block's mechanical system, and the processing difficulty of large internal combustion engine block should be solved. The method of virtual design and manufacturing technology and the application of modular and quick change fixture design are used to determine the reasonable process parameters; the technical problems of the local processing limitation in the machining field are simulated by combining the digital manufacturing technology, and this makes a beneficial attempt to the final machining technology of large internal combustion engine block; this paper expects to supply the theoretical information for final machining technology.

\section{Introduction to Basic Theory}

2.1. Introduction of L Type Engine Block. The holistic framework of $\mathrm{L}$ type internal combustion engine block is shown in Figure 1. Its gantry type structure makes it have excellent performance on antitorsion and bending performance. It can be defined as cylinder bore surface, bottom surface, flywheel surface, pump cover surface, and so forth. The main bearing cover which supports crankshaft is inverted at the lower part of the crankshaft, the crankshaft hole is machined after the combination with engine block, the camshaft hole is arranged in the intersection position of cylinder hole and surface and operating side, and the idler wheel hole and some positioning holes are all designed on the flywheel surface.
2.2. VM Technology. VM technology is a kind of technology which can simulate and predict the possible problems of the product function, performance, and machinability; it provides the $3 \mathrm{D}$ visualization environment from product concept formation to manufacturing; this makes the manufacturing technology out of the narrow world mainly relies on the experience [12].

The main means of VM technology is the simulation and virtual reality technology by high performance computer and high speed network; the product manufacturing process will be implemented, including product design, process planning, manufacturing, performance analysis, quality inspection, and process management and control. It is to become an indispensable means of developing new products with the help of the computer-aided design based on the 3D CAD/ CAE/CAM, and its function is to cover the entire life cycle.

Because of the complexity of the product design process, the design will lead a significant impact on the whole manufacturing process, so it needs a computer network collaborative work between the design department and the manufacturing department, through the comprehensive analysis of the product structure, product manufacturing, and product assembly using the performance evaluation system, so as to provide all the manufacturing process of the design and manufacturing information to users, as well as the corresponding modification function.

2.3. Modular Designs. The purpose of serialization is to meet the requirements of the demand side with the limited variety and specification of the products to the maximum extent and more economically and reasonably. Assembly is to use a lot of general series components and a small number of dedicated components for compounding complex products [13]. The generalization is to borrow the mature parts of the original products; it not only can shorten the design cycle and reduce costs but also can increase the quality of the product reliability. Due to the high degree of generalization, the parts can be manufactured separately from the factory's own department or the specialized factory. Haba and Oancea's products have a clear use function [14]. This function is composed of the product structure. There are several functions that can be achieved for a structure, due to the fact that the relationship between structure and function of mechanical products is not a one-to-one relationship $[6,15]$.

The modular design method considers that the product has a certain function of the realization of the overall structure of the module. We can achieve the overall product design through the combination of various structural modules.

\section{The Design of Modularization Fixture}

3.1. Modular Division of Engine Block. For the series of $\mathrm{L}$ type internal combustion engine block, their function of components is clear and relatively stable. It could be finished the machining step on NC Heavy-duty Gantry Milling machine by two fixture states. Although the number of cylinder holes is different with different engine block, the distance between the cylinder holes is equal; this is just one part of the reason, and other one is the same distribution between two sides, as 


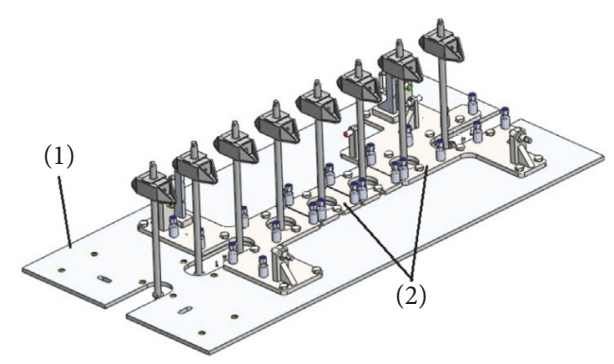

FIGURE 2: Structure of modular fixture. (1) Quick change positioning plate and (2) modular unit.

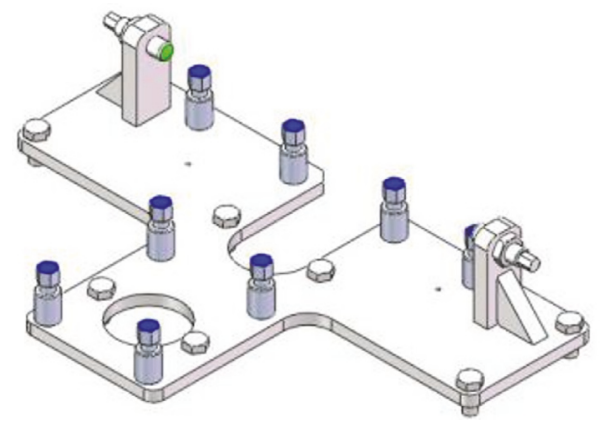

(a) Modular unit

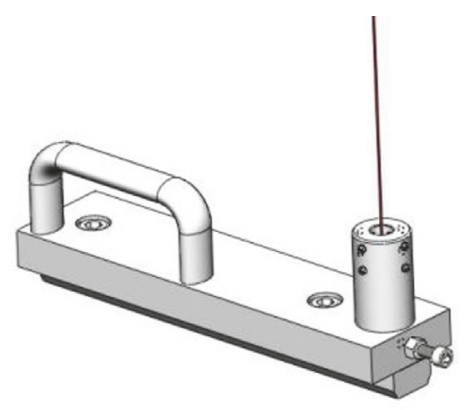

(b) The laser alignment device

FIGURE 3: The functional unit of fixture.

shown in Figure 1. Therefore, it is more appropriate to use the modular design method to design the fixtures in two states [7].

3.2. Modular Designs for Fixture. According to the above modular division of the engine block, on the premise that the large-scale gantry type milling machine is used as the processing equipment, we designed the tooling structure as shown in Figure 2.

In Figure 2, the fixture is mainly composed of a positioning base plate, a modular unit (see Figure 3(a)), and a laser automatic alignment unit (see Figure 3(b)).

Due to the thin-wall and high-precision requirements, all the machining parts are more than $80 \%$ of the engine block, and deformation and damage to the workpiece surface are easy to be caused, Therefore, the machining fixture of engine block must be strictly in accordance with the design of the

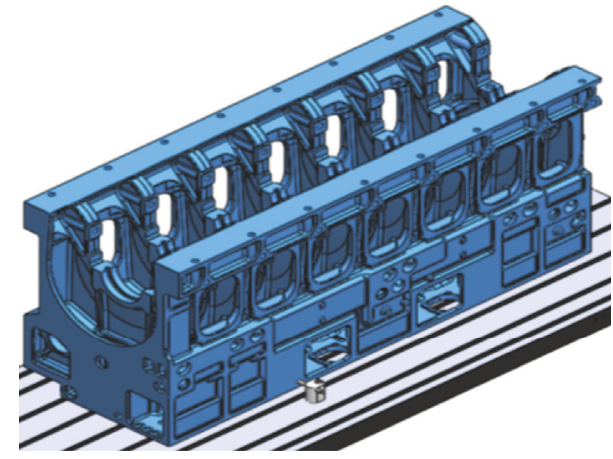

FIGURE 4: The final model of engine block.

product shape and process steps; the strength casting parts will be selected to increase the top of the support and compression unit to ensure the workpiece force balance. So the fixture with a positive and modular function is considered in the design.

The modular unit comprises a positioning block, a supporting bolt, and a locking device. Positioning block and the supporting bolt are welded on the designated position according to the internal structure of the internal combustion engine; the model is fixed on the $\mathrm{T}$ groove of the machine tool workbench by six-angle bolts and diamond blocks, and the engine block is arranged on the assembly fixture; then the special clamping plate is used to realize the rapid positioning and clamping.

This fixture can realize a unified positioning datum, which can meet the machining of different specifications of the engine block, and it reduces the repeated installation and disassembly time. So it provides a quick clamping positioning fixture for machining the cylinder block production line.

\section{Process Scheme Is \\ Based on VM Environment}

4.1. Design of Final Model of Engine Block. The main components of machining error are from clamping error and machine error; because of the inevitable error of machine tools, it is an effective way to improve the machining accuracy by virtual machining model.

According to the above method, the three-dimensional final mold is established in accordance with the finishing drawing; considering the deformation and finishing compensation of large-size engine block among finishing process, the overall tooling design is adopted in the virtual process to prevent the local deformation of the engine block in this study. An engine block model built up by applying boundary conditions is shown in Figure 4.

4.2. Simulation Model of Machining Process Based on VM Technology. From the manufacturing point of view, it is not the only one process route and process method to draw up a part; even if there is a conventional process, there are also some alternative process plans which are interchangeable. It will be fundamentally changed that the traditional 


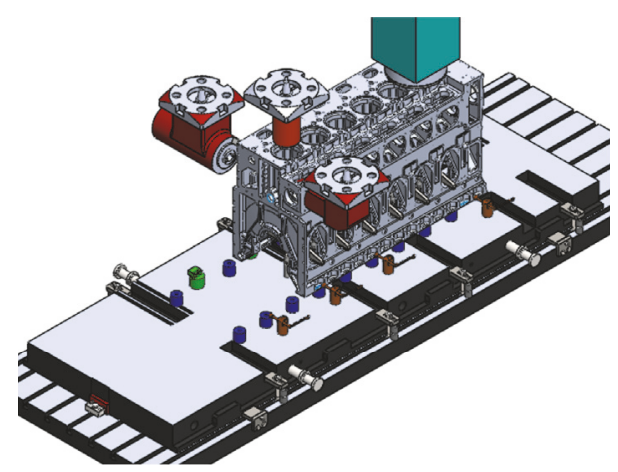

FIGURE 5: The simulation model of virtual manufacturing.

manufacturing modes of design, trial manufacture, modification design, and scale production by using VM technology.

Prior to the manufacture of the machine, first of all, we use a prototype production of virtual manufacturing environment to replace the traditional samples for testing and its performance and manufacturability are predicted and evaluated, thereby shortening the product design and manufacturing cycle, reducing product development costs and improving the ability of the system to respond quickly to market changes.

In this research, the computer-aided design is associated with the whole development process of the engine block. The machine model and related accessories model are established through precise drawing, as shown in Figure 5, and the limit parameters of machine are set to simulate the actual machining process by using computer software, such as the placement of the workpiece, process arrangement, and process optimization; the whole machining process is simulated through NX so that all kinds of problems may arise in the simulation of the actual processing. Therefore, we can formulate preventive measures according to the simulation results, in order to minimize the risk and also to evaluate the processing difficulties and optimize the process.

The simulation model was based on the $1: 1$ scale; the assembly process and the actual positioning datum were simulated according to the actual assembly process.

On this basis, the whole process of the engine block was simulated, and the key parts of the machine were studied; the processing method of the key parts of the engine block was summarized based on the experience of the existing box parts. In view of the length, the paper described the machining process of the deflection curve of the center hole of the crankshaft hole in the body structure.

4.3. Crankshaft Hole Machining Simulation with Disturbance Compensation. The crankshaft hole is the key part of the diesel engine, and its straightness is very demanding. If the internal combustion engine will run, the crankshaft hole straightness must be in accordance with the crankshaft deflection and the model design deflection curve shown in Figure 6. Therefore, it is very difficult to find the compensation law of straightness. In this paper, based on the research

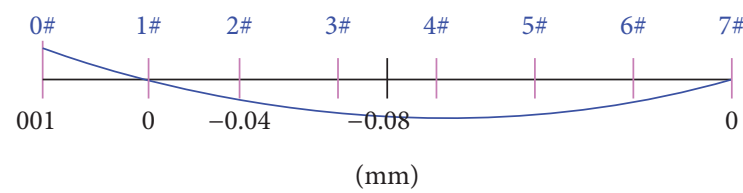

Figure 6: The design deflection curve of crankshaft hole of engine block.

TABLE 1: Machining compensation value of crankshaft hole center.

\begin{tabular}{lcccccccc}
\hline Crankshaft hole & $0 \#$ & $1 \#$ & $2 \#$ & $3 \#$ & $4 \#$ & $5 \#$ & $6 \#$ & $7 \#$ \\
Compensation value/mm & 0 & -0.005 & 0.02 & 0.05 & 0.06 & 0.05 & 0.03 & 0 \\
\hline
\end{tabular}

object of the L type engine block with seven cylinder holes, the machining process is simulated and analyzed.

In Figure 6, 0\#-7\# represent each cylinder of the 7 cylinder engine blocks; the corresponding values are the center deflection value of each cylinder. Therefore, it is required that the center line of the crankshaft hole is not a straight line in the height direction of the engine block but is a curve with deflection, and the maximum is located in the middle.

In the process of simulation, the machining process of crankshaft hole is from 0 \# crankshaft holes to the last one, that is, the order processing. In the simulation, it is found that the accessories will interfere because the distance between $0 \#$ and $1 \#$ is too small, so the processing sequence is set as $0 \#-2 \#-7 \#$, and then the machine tool accessories are turned over, then to process the $3 \#$ crankshaft hole center to find the correct processing of $1 \#$. The results of Figure 7 are obtained by simulating the machining process by using Table 1 data.

The basic trend of the compensation value is consistent with the requirements, but the position of $2 \#$ crankshaft hole is in the opposite direction; the analysis of the process can be seen:

(1) In regard of the program, the maximum compensation value be set at the position of $3 \#$ crankshaft hole but from the measurement results obtained that the lowest compensation value is located in the position of $4 \#$ crankshaft hole, and the compensation value of $1 \#$ crankshaft hole is 0 , while the actual value is $0.02 \mathrm{~mm}$. We can draw the conclusion that the curvature of the crankshaft hole center does not change according to the law of the compensation value.

(2) In terms of the process, the $1 \#$ crankshaft hole will be machined based on the datum which is according to the $3 \#$ crankshaft hole center. This method makes the $1 \#$ crankshaft hole consistent with the position of the $3 \#$ crankshaft hole, as shown in the results of the measurement curve, so the process will affect the processing results of the crankshaft hole.

In order to get a curve that continues to rise from zero to the lowest point, it is necessary to improve the virtual machining process. Therefore, the processing sequence is changed to that the $0 \#$ crankshaft will be machined firstly, skipping $1 \#$, then machining the rest of the number $2 \#$ to number $7 \#$ in order, and finally turning the machine tool 
TABLE 2: The compensation value of crankshaft hole center.

\begin{tabular}{lcccccccc}
\hline The position of crankshaft hole & $0 \#$ & $1 \#$ & $2 \#$ & $3 \#$ & $4 \#$ & $5 \#$ & $6 \#$ & $7 \#$ \\
The compensation value $/ \mathrm{mm}$ & 0.03 & 0 & -0.03 & -0.05 & -0.06 & -0.05 & -0.03 & 0 \\
\hline
\end{tabular}

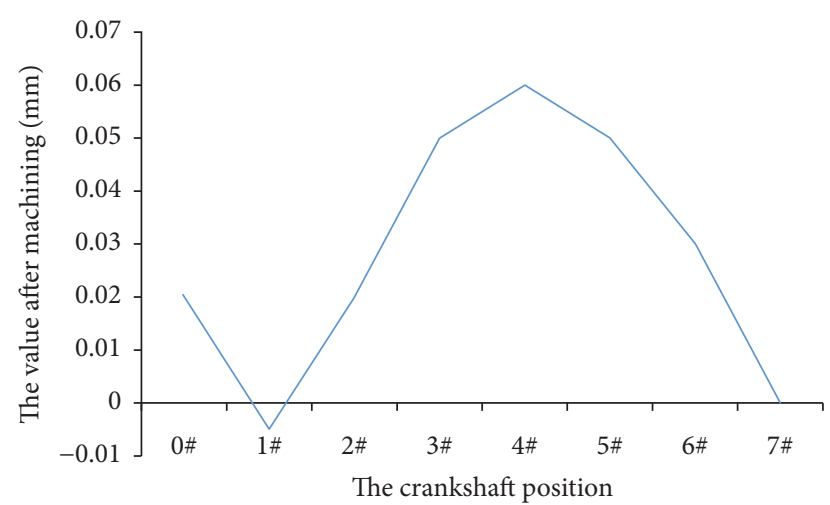

Figure 7: Distribution diagrams of the simulation of crankshaft hole.

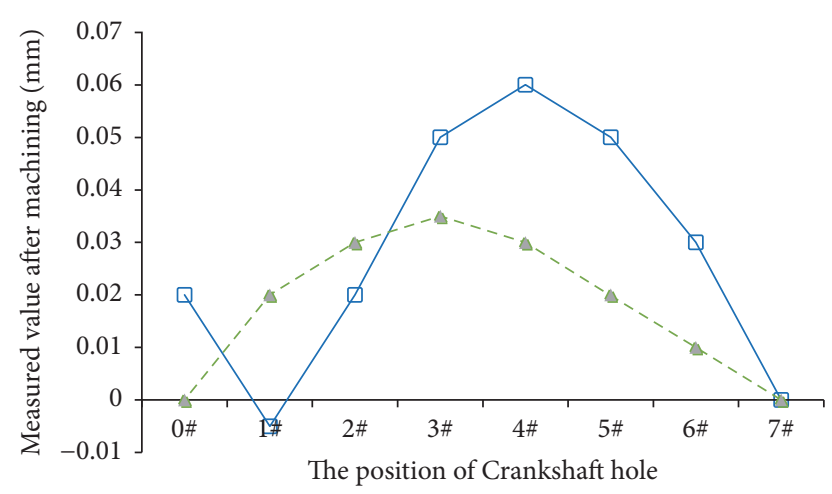

FIgURE 8: The distribution contrast diagram of crankshaft holes.

accessories; the 1\# crankshaft hole was machined according to the center of completed 2\# crankshaft hole; this method can ensure that the compensation value of $1 \#$ crankshaft hole is always zero, and the compensation value of $2 \#$ crankshaft is close to the value of $1 \#$. On the basis of this process, the results are shown in Figure 8 (contrast Figure 7) by means of repeated simulation, the compensation value shown in Table 2.

In Figure 8, the solid line is measurement results before process improvement, and the dotted line is after improvement results. According to the improved processing technology, the machining allowance of the crankshaft hole is reduced, and so is the cutting force; on the contrary, the stability of the straightness data is improved. At the same time, the compensation value of the program is modified to ensure that the lowest point of the curve is near the middle position, and there is a trend of decreasing on both sides of the peak.

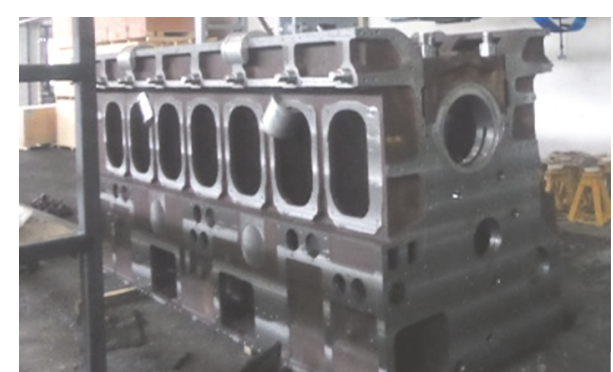

FIgURE 9: The sample of fine processing of L type engine block.

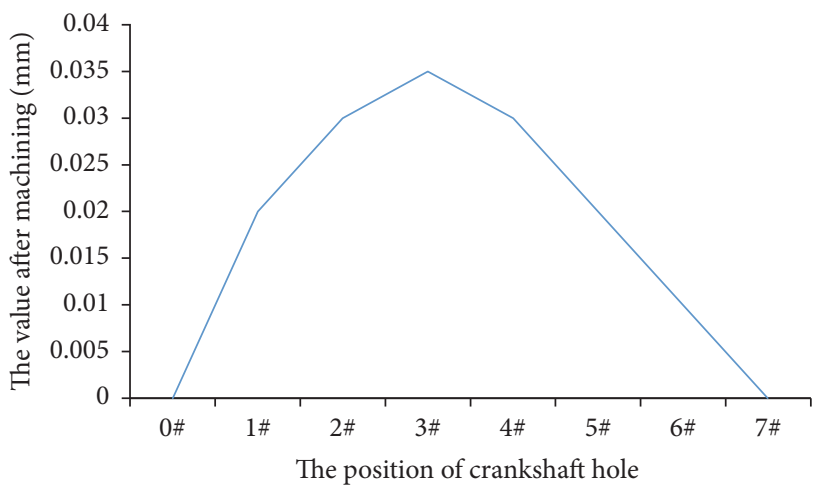

FIGURE 10: The distribution diagram of crankshaft hole of sample processing.

\section{Premachining Experiment}

According to the technology of the modular chemical assembly structure and simulation module, in strict accordance with the basic production tooling drawings, a L type internal combustion engine block was be machined by using large gantry milling tool in accordance with the optimized process scheme; the finished machining engine block is as Figure 9; the sizes of this finished engine block were measured by threecoordinate detection system and compared with the size of the drawing. Taking the high accuracy crankshaft holes as an example, the following measurement results are drawn, as shown in Figure 10.

Comparison of the simulation results shows that premachining results based on VM technology are the same as simulation results, the crankshaft hole straightness of the improved process to achieve the desired results; both the straightness compensation amount or changing tendency meet the requirements.

\section{Discussions}

This provides a contrast with the existing comparison between the premachining test results and the simulation 
results, as the use of virtual manufacturing technology with the development process of the engine block can be seen. Through the establishment of processing equipment, special accessories, and final machine model, the parameters of machine tools are set, and we can do the following sequence, that is, the simulation of the actual process, optimization of processing technology, evaluation of processing difficulties, and other measures. Therefore, these work can improve the success rate of the first piece of machining and effectively solve the key technology of the body; this will ensure that the actual processing results are consistent with the simulation results; both the size precision and the shape precision have reached the design accuracy of the drawings.

\section{Conclusions}

This paper is a contribution to the subject of process planning for the final machining on internal combustion engine block. The key machining process technology of L type internal combustion engine block was studied based on VM technology; the main conclusions were as follows:

(1) The simulation of the machining process based on virtual manufacturing technology can accurately evaluate the machining difficulties, make effective measures, and optimize the processing technology. According to the secondary prevention, this study has broken through the key machining technology of large internal combustion engine block.

(2) It is proved that the simulation of the machining process based on virtual manufacturing technology can effectively guide the field processing, which is an effective attempt for the virtual manufacturing technology.

(3) According to the modular and quickly changed fixtures of the processing tools to meet the same type of different types of machine body positioning, it can greatly improve the efficiency of the clamp.

This paper aims to establish a final machining method of large internal combustion engine block with virtual manufacturing technology. It would be of considerable interest not only to continue these studies, in relation to final process frame, but also to promote the processing technology of largescale machine.

\section{Conflicts of Interest}

The authors declare that they have no conflicts of interest.

\section{Acknowledgments}

The authors acknowledge the support to this research and thanks are due to Fan Peng for assistance with the experiments and for valuable discussion. This work was partially supported by the National Natural Science Foundation of China (2017A0497).

\section{References}

[1] G. Timelli, D. Caliari, and J. Rakhmonov, "Influence of process parameters and sr addition on the microstructure and casting defects of lpdc a356 alloy for engine blocks," Journal of Materials Science and Technology, vol. 32, no. 6, pp. 515-523, 2016.

[2] X. B. Yun and B. Y. Song, "sVirtual manufacturing and its applications in plastic forming," Journal of Plasticity Engineering, vol. 10, no. 06, pp. 49-52, 2003.

[3] J. Ciurana, I. Ferrer, and J. X. Gao, "Activity model and computer aided system for defining sheet metal process planning," Journal of Materials Processing Technology, vol. 173, no. 2, pp. 213-222, 2006.

[4] W. Cai, S. J. Hu, and J. X. Yuan, "Deformable sheet metal fixturing: principles, algorithms, and simulations," Journal of Manufacturing Science \& Engineering, vol. 118, no. 3, pp. 318-324, 1996.

[5] T. HCZhang and Z. C. Liu, "Diesel engine block remanufacturing: life cycle assessment," Handbook of Manufacturing Engineering and Technology, vol. 30, no. 9, pp. 3313-3341, 2014.

[6] J. Q. Xie, J. S. Agapiou, D. A. Stephenson, and P. Hilber, "Machining Quality Analysis of an Engine Cylinder Head Using Finite Element Methods," Journal of Manufacturing Processes, vol. 5, no. 2, pp. 170-184, 2003.

[7] C. Dietz, K. Wegener, and W. Thyssen, "Continuous generating grinding: Machine tool optimisation by coupled manufacturing simulation," Journal of Manufacturing Processes, vol. 23, pp. 211221, 2016

[8] A. A. Kadir and X. Xu, "Towards high-fidelity machining simulation," Journal of Manufacturing Systems, vol. 30, no. 3, pp. 175186, 2011.

[9] R. Kurczab, S. Smusz, and A. J. Bojarski, "Evaluation of different machine learning methods for ligand-based virtual screening," Journal of Cheminformatics, vol. 3, no. 1, article no. P41, 2011.

[10] J. K. Gershenson, G. J. Prasad, and S. Allamneni, "Modular product design: a life - cycle View," Journal of Integrated Design \& Process Science, vol. 3, no. 4, pp. 1-9, 1999.

[11] V. B. Kreng and T.-P. Lee, "Modular product design with grouping genetic algorithm - A case study," Computers \& Industrial Engineering, vol. 46, no. 3, pp. 443-460, 2004.

[12] D. Chen, "A methodology for developing service in virtual manufacturing environment," Annual Reviews in Control, vol. 39, pp. 102-117, 2015.

[13] F. Eichler, J. Kahrstedt, E. Pott, and H. Beddies, “The new threecylinder engine from volkswagen's modular diesel engine system," MTZ worldwide, vol. 75, no. 7-8, pp. 18-25, 2014.

[14] S. A. Haba and G. Oancea, "Digital manufacturing of air-cooled single-cylinder engine block," The International Journal of Advanced Manufacturing Technology, vol. 80, no. 5-8, pp. 747759, 2015

[15] P. Haghighi, S. Ramnath, N. Kalish, J. V. Shah, J. J. Shah, and J. K. Davidson, "Method for automating digital fixture-setups that are optimal for machining castings to minimize scrap," Journal of Manufacturing Systems, vol. 40, pp. 15-24, 2016. 


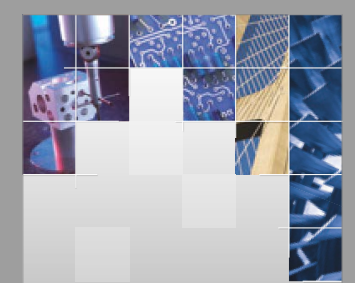

\section{Enfincering}
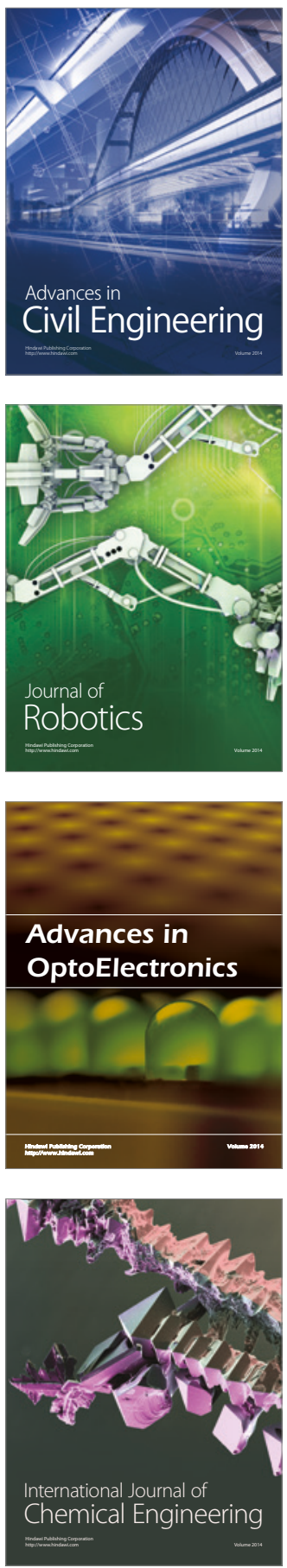

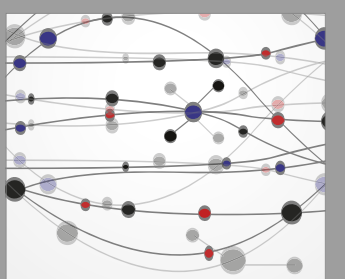

The Scientific World Journal

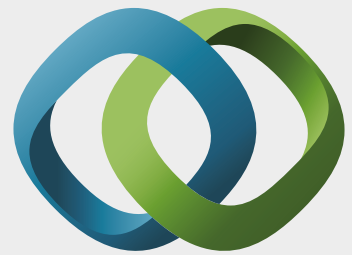

\section{Hindawi}

Submit your manuscripts at

https://www.hindawi.com
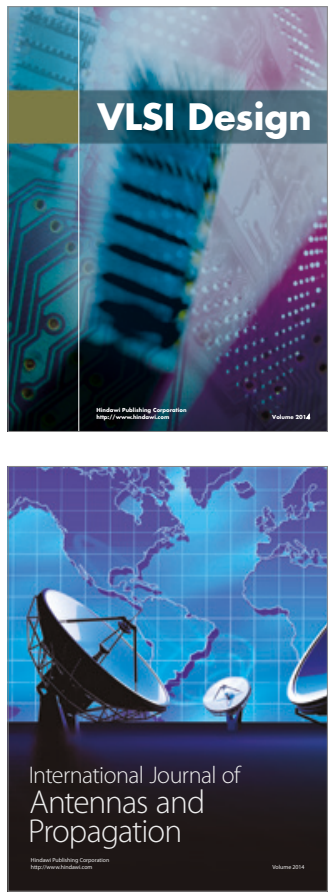

\section{Rotating}

Machinery
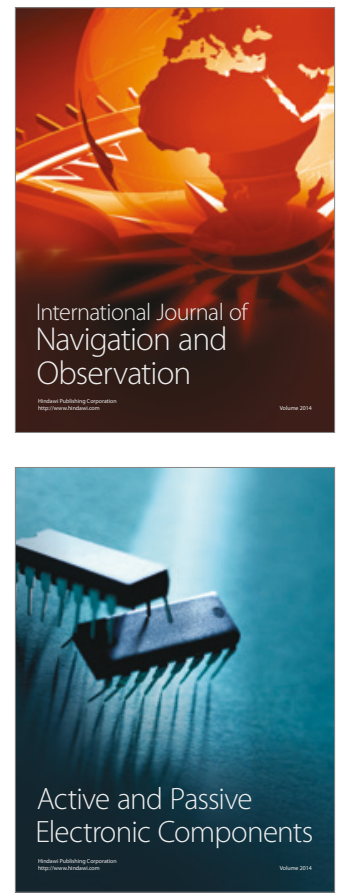
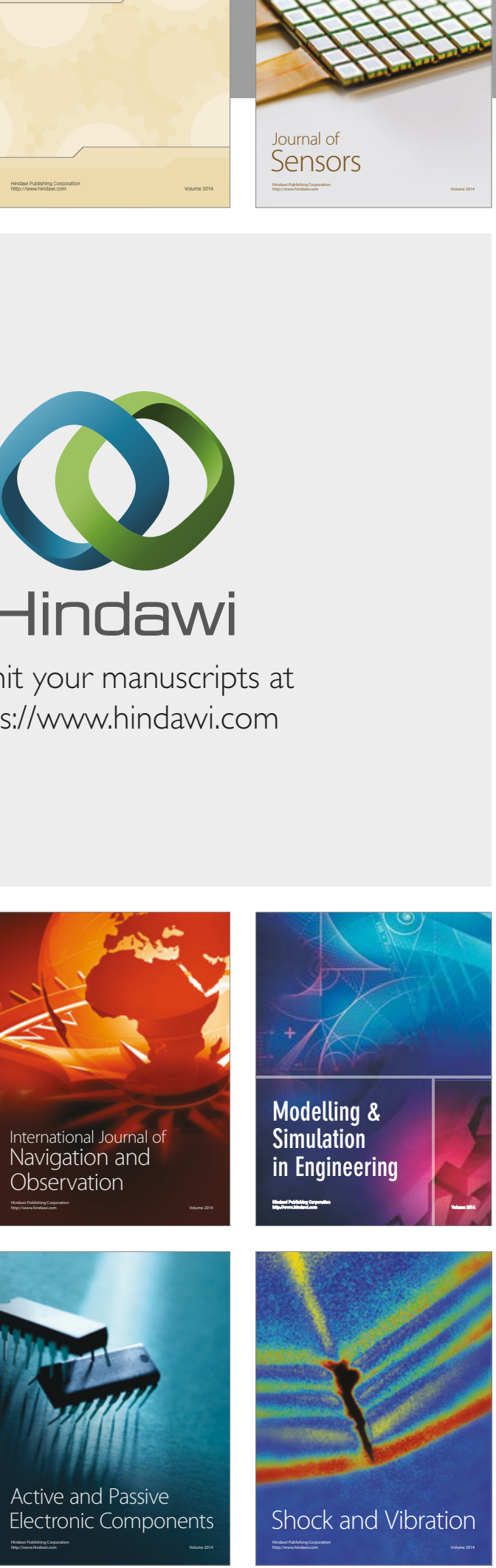
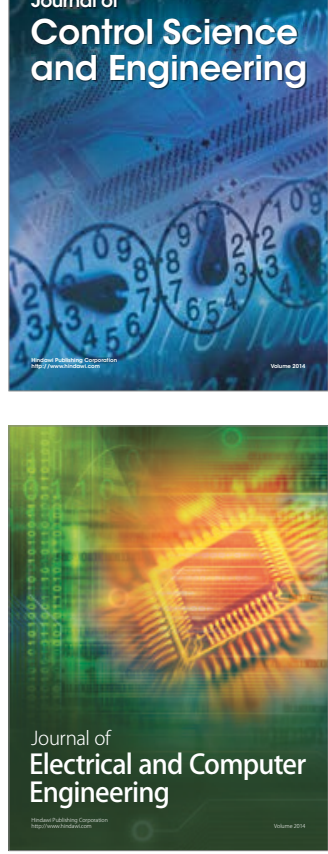

Distributed

Journal of

Control Science

and Engineering
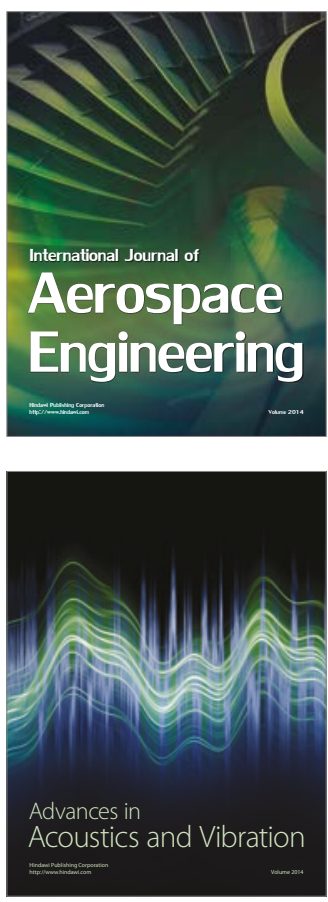

Sensor Networks 